\title{
Newborn traits associated with pre-weaning growth and survival in piglets
}

\author{
Morakot Nuntapaitoon ${ }^{1}$, Ramon Muns ${ }^{2}$, and Padet Tummaruk ${ }^{1, *}$
}

* Corresponding Author: Padet Tummaruk Tel: +66-2-2189644-5, Fax: +66-2-252-0738,

E-mail: Padet.t@chula.ac.th

${ }^{1}$ Department of Obstetrics, Gynaecology and Reproduction, Faculty of Veterinary Science, Chulalongkorn University, Bangkok 10330, Thailand ${ }^{2}$ Agri-Food and Biosciences Institute, Co Down, Northern Ireland BT 26 6DR, United Kingdom

ORCID

Padet Tummaruk

https://orcid.org/0000-0001-7000-4371

Submitted Dec 16, 2016; Revised Mar 10, 2017; Accepted Jul 10, 2017
Objective: Piglet pre-weaning mortality is an important variable indicating the efficacy of farrowing management and animal well-being during lactation. The present study determined the association of newborn traits measured soon after birth with piglet pre-weaning mortality and growth.

Methods: In total, 805 piglets born from 57 multiparous sows were investigated. Their blood oxygen saturation, blood glucose and rectal temperature at $24 \mathrm{~h}$ after birth (RT24h) were monitored. Birth order, sex, skin color, integrity of the umbilical cord, attempts to stand and birth intervention were monitored. Piglets were weighed at day 0,7 , and 21 to evaluate average daily gain (ADG).

Results: Piglet pre-weaning mortality for lactation period was $12.6 \%$ and cumulative mortality during the first 7 days of age was $8.6 \%$. A higher proportion of piglets with pale skin color died compared to piglets with normal skin color $(26.7 \%$ vs $7.7 \%, \mathrm{p}<0.001)$. A higher $(\mathrm{p}<0.001)$ proportion of piglets that attempted to stand after $5 \mathrm{~min}(38.5 \%)$ died compared to piglets that attempted to stand within $1 \mathrm{~min}(6.3 \%)$ after birth. Piglet body weight at birth $\left(\mathrm{BW}_{\mathrm{B}}\right)$, blood glucose and the number of piglets born alive (BA) were correlated with ADG $(p<0.05)$. Piglets with $\mathrm{BW}_{\mathrm{B}}<1.30 \mathrm{~kg}$ had higher $(\mathrm{p}<0.001)$ mortality rate than piglets with $\mathrm{BW}_{\mathrm{B}} \geq 1.80 \mathrm{~kg}(19.0 \%$ vs $3.3 \%)$ and piglets with $\mathrm{BW}_{\mathrm{B}} 1.30$ to $1.79 \mathrm{~kg}(4.0 \%)$. Piglet with $\mathrm{RT} 24 \mathrm{~h}<37.0^{\circ} \mathrm{C}$ had higher $(\mathrm{p}<0.001)$ mortality rate $(86.2 \%)$ than piglets with $\mathrm{RT} 24 \mathrm{~h}>38.5^{\circ} \mathrm{C}(3.9 \%)$.

Conclusion: Low BW $\mathrm{B}_{\mathrm{B}}$ and low RT24h compromise piglet survival during the lactation period in the tropical conditions. Piglets in the litters with a high $\mathrm{BA}$, low $\mathrm{BW}_{\mathrm{B}}$ and low blood glucose have reduced $\mathrm{ADG}$.

Keywords: Average Daily Gain; Birth Weight; Mortality; Newborn Traits; Pig

\section{INTRODUCTION}

In modern swine industry, producers expect up to 30 pigs weaned per sow per year [1]. However, in practice, a high proportion of piglet mortality occur during pre-weaning period [2]. Thus, factors associated with piglet pre-weaning mortality are becoming a major concern in swine industry worldwide [3]. One of main reason for a high proportion of piglet pre-weaning mortality is the use of high prolific sow genetics, which improved the number of piglets born alive per litter among swine commercial herds worldwide during the past 10 years [1]. Litter size (LS) is an important sow factor related to piglet survival and growth [2]. Nuntapaitoon and Tummaruk [2] demonstrated that piglet pre-weaning mortality in the litter with 13 to 15 littermate pigs $(24.1 \%)$ was significantly higher than the litter with 1 to $7(11.9 \%), 8$ to $10(11.8 \%)$, and 11 to $12(14.6 \%)$ littermate pigs, respectively. Large LS also increases the body weight at birth $\left(\mathrm{BW}_{\mathrm{B}}\right)$ variation among the piglets within litter [4]. Hence, the proportion of piglets with low $\mathrm{BW}_{\mathrm{B}}$ is also increased [5]. Vallet and Miles [6] observed that low $\mathrm{BW}_{\mathrm{B}}$ piglets had a higher risk of being crushed due to their slower speed of movement and reflexive actions. Intra-partum hypoxia is a main factor influenc- 
ing piglet vitality as it damages the foetal central nervous system [7]. Thus, several indicators can be used in newborn piglets to evaluate the level of intra-partum hypoxia suffered during the birth process. In addition, piglet vitality determines their capacity to suckle and compete for a teat and is also positively correlated with piglet growth and survival until weaning [8]. One reason for reduced piglet vitality might be related to nutrients and oxygen supplies via umbilical cord from dam to fetus. Blood oxygen, blood glucose concentration, and time to stand after birth have been used as indirect measures of intra-partum hypoxia and neonatal piglet viability [9].

Factors influencing piglet pre-weaning mortality under field conditions include sow factors (e.g., breed, parity, nutritional status, farrowing duration, maternal behavior and LS), piglet factors (e.g., $\mathrm{BW}_{\mathrm{B}}$, birth order and sex) and environmental factors (e.g., ambient temperature and stocking density) $[2,9]$. To our knowledge, most of the studies on risk factors associated with piglet pre-weaning mortality were performed in cold or moderate climates [10-12]. Additional information in hot and humid climate countries is required to improve farrowing management and care of newborn piglets. The objective of the present study was to determine the effects of piglet neonatal traits and physiological characteristics measured soon after birth on their pre-weaning survival and growth.

\section{MATERIALS AND METHODS}

\section{Animal care}

The experiment followed the guidelines documented in The Ethical Principles and Guidelines for the Use of Animals for Scientific Purposes edited by the National Research Council of Thailand, and was approved by the Institutional Animal Care and Use Committee (IACUC) in accordance with the university regulations and policies governing the care and use of experimental animals (approval no. 1431063).

\section{Herd and management}

The present study was carried out in a 3,500-sows commercial swine herd in the western part of Thailand between June and August 2013. The average ambient temperature during the experimental period ranged from $25.8^{\circ} \mathrm{C}$ to $30.0^{\circ} \mathrm{C}$. The minimum and maximum temperature ranged from $21.1^{\circ} \mathrm{C}$ to $26.3^{\circ} \mathrm{C}$ and from $28.1^{\circ} \mathrm{C}$ to $37.6^{\circ} \mathrm{C}$, respectively. The average relative humidity varied from $72.0 \%$ to $96.0 \%$. Sows were kept in individual crates $\left(1.2 \mathrm{~m}^{2}\right)$ during gestation in a conventional open-housing system and were provided with fans and individual water sprinklers to reduce the impact of high ambient temperature. During gestation, sows were fed a commercial gestation diet that met or exceed their nutritional requirement estimates (19.7\% crude protein, $5.8 \%$ fat, 3.8\% fibre, and 14.0 metabolizable energy, MJ/kg) [13]. Feed was provided twice a day following a standardised feeding pattern, resulting in an average of $2.5 \mathrm{~kg}$ per sow per day. During lacta- tion, sows were fed twice a day with a commercial lactation diet, increasing the daily amount of feed offered, until ad libitum feed was reached after one week of lactation. The animals were received water ad libitum in a continuous water channel. Pregnant sows were moved to the farrowing house about one week before their expected farrowing date. Sows were kept in individual farrowing crates $\left(1.2 \mathrm{~m}^{2}\right)$ placed at the centre of the pens with a space allowance of $4.2 \mathrm{~m}^{2}$. The pens were fully slatted with concrete at the centre for sows and with steel slats at both sides of the farrowing crate for piglets. Each pen was provided with a creep area for piglets $\left(0.60 \mathrm{~m}^{2}\right)$ placed on the floor on one side, covered by a plastic plate and heating lamp during the first week after farrowing. The heating lamp was usually turned on during the night or when the environment temperature fell below $30^{\circ} \mathrm{C}$. The temperature in the creep area was between $30^{\circ} \mathrm{C}$ to $36^{\circ} \mathrm{C}$.

\section{Supervision of parturition process}

The parturition process was carefully supervised by the first author (M. Nuntapaitoon). Briefly, sows were interfered with as little as possible during parturition, and birth intervention was performed only when dystocia was clearly identified. Dystocia was considered when an interval of $>30$ min elapsed from the birth of the last piglet, and when the sow showed intermittent straining accompanied by paddling of the legs or when the sow expelled small quantities of foetal fluid together with marked tail switching for $>30$ min without any piglet being born. Routine procedures performed on piglets included weighing, tail docking, tooth clipping and $1 \mathrm{~mL}(200 \mathrm{mg})$ iron supplement administered intramuscularly (Gleptosil, Alstoe Ltd. Animal Health, Leicestershire, England) on the day of birth. Piglets were orally administered a coccidiocide of $20 \mathrm{mg} / \mathrm{kg}$ body weight (Baycox [Toltrazuril 5.0\% oral suspension], Bayer Inc., Mississauga, ON, Canada) to control neonatal coccidiosis at 3 days of age. In total, 805 piglets born from 57 Landrace $\times$ Yorkshire crossbred sows were included. The mean parity was $4.0 \pm 1.6$ (ranged 2 to 7 ). Lactation length was on an average of $23.0 \pm 2.0$ days.

\section{Data collection}

The following reproductive variables of the sows were recorded: farrowing duration (i.e., time between the first and last born piglets), total number of piglets born per litter (TB), number of piglets born alive per litter (BA), and mummified foetuses, stillbirths and number of piglets at weaning per litter. The piglets' heart rate and blood oxygen saturation $\left(\mathrm{SatO}_{2}\right)$ were monitored within $5 \mathrm{~min}$ after birth by using a veterinary pulse oximetry (EDAN VE-H100B Pulse Oximeter, Edan Instrument Inc., San Diego, CA, USA). Thereafter, blood samples for glucose analysis were collected from piglets within 5 to $10 \mathrm{~min}$ after birth (i.e., before first suckling). A small amount of blood sample (a mixture of venous and arterial blood) was obtained from the cut umbilical cord. Few drops of blood sample were used to determined blood glucose concentration by using a portable test kit of human 
glucometer (Accu-Chek Performa, Roche, Mannheim, Germany). Birth order, birth interval (the time elapsed between each piglet born), sex, and time elapsed from birth until first attempts to stand ( 3 groups: $<1 \mathrm{~min}, 1$ to $5 \mathrm{~min}$, and $>5 \mathrm{~min}$ ) were recorded for each piglet. Also, birth assistance was recorded (yes or no) if required by piglets. Skin color of the piglets was recorded at birth and was classified into 2 groups (normal or pale). Integrity of the umbilical cord of each piglet was examined and classified into two groups (intact or broken). Rectal temperature was measured at $24 \mathrm{~h}$ after birth (RT24h) with a digital thermometer (Microlife, Microlife AG Swiss Corporation, Widnau, Switzerland, with a display resolution of $0.01^{\circ} \mathrm{C}$ and $\pm 0.1^{\circ} \mathrm{C}$ accuracy). All piglets were individually identified by an ear tattoo. Body weight of the piglets was measured immediately at birth. Litters were equalized to 13 or 14 piglets per litter after $24 \mathrm{~h}$ and within $48 \mathrm{~h}$ after birth. The LS was defined as the number of piglets after cross-fostering. Piglets were weighed again at day 7 and 21 after birth. Mortality rate of the piglets was also determined at day 7 and 21 of lactation. Creep feeding and drinking water were provided to the piglets from 7 days of age until weaning.

\section{Statistical analysis}

All statistical analyses were performed using SAS 9.0 (SAS Inst. Inc., Cary, NC, USA) [14]. Descriptive analysis (mean \pm standard deviation $[\mathrm{SD}]$ median and range) and frequency analysis were obtained for all reproductive parameters. To identify the potential indicators for piglet mortality and piglet average daily weight gain (ADG) at days 7 and 21 of lactation, each recorded factor was individually tested using univariate analyses. Continuous variables indicating the neonatal piglet characters (i.e., TB, BA, $\mathrm{LS}$, birth order, $\mathrm{BW}_{\mathrm{B}}$, birth interval, heart rate, $\mathrm{SatO}_{2}$ and blood glucose concentration) were compared between piglets dying and surviving at days 7 and 21 of lactation by using Student's $t$ test (PROC TTEST). The association between categorical variables (i.e., sex, skin color, attempts to stand, umbilical cord integrity and birth assistance) and the piglet mortality (dead or alive) were analyzed using Chi-square test. The effect of these categorical variables on $A D G$ at days 7 and 21 of lactation was analyzed using the PROC GLM of SAS. Pearson's correlation was performed to study collinearity among the continuous variables in the univariate models.

For multivariate analyses, generalised linear mixed models (GLMMIX macro) with the dependent variable (mortality) modeled as a binary outcome (dead or alive) was conducted. Factors with significant levels of $\mathrm{p}<0.10$ were included in the final models. Highly correlated variables were not included in the same multivariate analyses models. Then, the final multivariate GLMMIX models for piglet mortality at days 7 and 21 of lactation included $\mathrm{BW}_{\mathrm{B}}$ of the piglet classes $(<1.30,1.30$ to 1.79 , and $\geq 1.80$ $\mathrm{kg})$ and RT24h classes $\left(<37.0^{\circ} \mathrm{C}, 37.0^{\circ} \mathrm{C}\right.$ to $38.5^{\circ} \mathrm{C}$, and $\left.>38.5^{\circ} \mathrm{C}\right)$. The classification of the independent variables was made according to frequency distribution with some minor adjustment based on biological reliability. Similarly, general linear mixed models (PROC MIXED) were conducted to analyze piglet ADG at days 7 and 21 of lactation. The final multivariate MIXED models for piglet $\mathrm{ADG}$ at day 7 and 21 included $\mathrm{BW}_{\mathrm{B}}$ classes $(<1.30,1.30$ to 1.79 , and $\geq 1.80 \mathrm{~kg}$ ), blood glucose concentration classes ( $\leq 24$ and $>24 \mathrm{mg} / \mathrm{dL}$ ), BA classes ( $<12,12$ to 14 , and $\geq 15$ piglets), sex and attempts to stand ( $<1,1$ to 5 , and $>5 \mathrm{~min}$ ). In all models, sow or litter were introduced as a random effect. Least squares means were obtained from each class of the variables and were compared using Tukey-Kramer adjustment for multiple comparisons. $\mathrm{p}<$ 0.05 was regarded to be statistically significance and $0.05<\mathrm{p}<0.10$ was considered as a tendency for statistically significance. Piglets were defined as experimental units.

\section{RESULTS}

Of the 805 piglets, 81 were stillborn (10.1\%), 34 were mummified fetuses $(4.2 \%)$ and 690 were BA (85.7\%). Descriptive statistics of newborn piglet traits and piglet performance are presented in Table 1. On average (means $\pm S D$ ), TB, BA, and the number of piglets at weaning were $14.2 \pm 3.7,12.1 \pm 3.4$, and $11.7 \pm 1.7$ piglets, respectively. The duration of farrowing averaged $217.8 \pm 83.7 \mathrm{~min}$, and the average birth interval between piglets was $16.4 \pm 24.1 \mathrm{~min}$. Overall, piglet pre-weaning mortality was $12.6 \%$ and cumulative mortality at day 7 was $8.6 \%$.

Table 1. Descriptive statistics of 690 piglets evaluated at birth and during the lactation period

\begin{tabular}{lcccc}
\hline Variables & N & Mean \pm SD & Median & Range \\
\hline Birth weight $(\mathrm{kg})$ & 690 & $1.49 \pm 0.38$ & 1.48 & 0.46 to 2.71 \\
Heart rate $(\mathrm{bpm})$ & 685 & $66.2 \pm 33.20$ & 57.0 & 23.0 to 250 \\
Glucose $(\mathrm{mg} / \mathrm{dL})$ & 687 & $49.1 \pm 17.72$ & 47.0 & 11.0 to 159 \\
Oxygen saturation $(\%)$ & 685 & $91.2 \pm 8.85$ & 92.0 & 10.0 to 100 \\
Rectal temperature at $24 \mathrm{~h}\left({ }^{\circ} \mathrm{C}\right)$ & 670 & $38.7 \pm 0.57$ & 38.7 & 35.5 to 40.3 \\
Weight at day 7 $(\mathrm{kg})$ & 632 & $2.67 \pm 0.71$ & 2.7 & 0.75 to 4.64 \\
Weight at day 21 $(\mathrm{kg})$ & 602 & $6.09 \pm 1.51$ & 6.1 & 1.88 to 10.07 \\
ADG at day 7 $(\mathrm{g} / \mathrm{d})$ & 632 & $163.7 \pm 67.32$ & 164.6 & -7.9 to 340.7 \\
ADG at day 21 $(\mathrm{g} / \mathrm{d})$ & 602 & $216.8 \pm 63.05$ & 213.3 & 24.0 to 376.9 \\
\hline
\end{tabular}

SD, standard deviation; $A D G$, average daily gain. 


\section{Univariate analyses}

Factors associated with piglet pre-weaning mortality until day 7 after birth: Factors influencing piglet pre-weaning mortality rate until day 7 after birth are presented in Tables 2, 3. Both $\mathrm{BW}_{\mathrm{B}}$ and RT24h influenced piglet mortality until day 7 after birth $(\mathrm{p}<$ $0.001)$. Piglets that died before day 7 of life had a lower birth interval (9.5 vs $14.9 \mathrm{~min}, \mathrm{p}=0.005)$ and were reared in litters with a higher LS (13.7 vs 13.2 piglets, $\mathrm{p}=0.038$ ). The total number of piglets born per litter, $\mathrm{BA}$, birth order, heart rate, $\mathrm{SatO}_{2}$, and blood glucose concentration did not influence piglet survival ( $p>0.05$, Table 2 ). A higher proportion of piglets with pale skin color died compared to piglets with normal skin color $(26.7 \%$ vs $7.7 \%$; $\mathrm{p}<0.001$, Table 3 ). A higher proportion of piglets that attempted to stand after $5 \mathrm{~min}$ (38.5\%) died compared to piglets that attempted to stand within $1 \mathrm{~min}(6.3 \%, \mathrm{p}<0.001)$ and within 1 to $5 \mathrm{~min}(9.2 \%, \mathrm{p}<0.001$, Table 3$)$. Birth intervention, sex and umbilical cord integrity had no effect on piglet mortality until day 7 after birth ( $\mathrm{p}>0.05$, Table 3$)$.

Factors associated with piglet pre-weaning mortality until day 21 after birth: Factors influencing piglet pre-weaning mortality rate until day 21 after birth are presented in Table 3, 4. Both $\mathrm{BW}_{\mathrm{B}}$ and RT24h influenced piglet mortality until day 21 after birth $(p<0.001)$. Piglets that died before day 21 of life were born from sows with a higher $\mathrm{TB}$, were reared in litters with a higher LS, and had lower birth intervals ( $\mathrm{p}<0.05$, Table 4$)$. Birth order, heart rate, $\mathrm{SatO}_{2}$ and blood glucose concentration did not influence piglet survival ( $p>0.05$, Table 4). A higher proportion of piglets with pale skin color died compared to piglets with normal skin color (36.7\% vs $11.5 \%$; $\mathrm{p}<0.001$, Table 3 ). A higher proportion of piglets that attempted to stand after $5 \mathrm{~min}(41.0 \%)$ died compared to piglets that attempted to stand within $1 \mathrm{~min}(10.8 \%, \mathrm{p}<0.001)$ and within 1 to $5 \mathrm{~min}(10.8 \%, \mathrm{p}<0.001$, Table 3$)$. Birth intervention, sex and umbilical cord integrity had no effect on piglet mortality until day 21 after birth ( $>>0.05$, Table 3$)$.

Factors associated with average daily gain until day 7 after birth: Piglet $\mathrm{BW}_{\mathrm{B}}(\mathrm{p}<0.001)$ and blood glucose concentration $(\mathrm{p}<0.001)$ positively influenced piglet ADG at day $7(\mathrm{r}=0.172, \mathrm{p}<0.001$, Table 5). Piglets born from sows with higher TB and higher BA
Table 3. Categorical variables influencing piglet pre-weaning mortality at day 7 and 21 after birth

\begin{tabular}{lcc}
\hline \multirow{2}{*}{ Variables } & \multicolumn{2}{c}{ Piglet pre-weaning mortality (\%) } \\
\cline { 2 - 3 } & Day 7 & Day 21 \\
\hline Skin color & & \\
$\quad$ Normal & $7.7^{\mathrm{a}}$ & $11.5^{\mathrm{a}}$ \\
$\quad$ Pale & $26.7^{\mathrm{b}}$ & $36.7^{\mathrm{b}}$ \\
Time attempted to stand & & \\
$\quad<1$ min & $6.3^{\mathrm{a}}$ & $10.8^{\mathrm{a}}$ \\
1 to 5 min & $9.2^{\mathrm{a}}$ & $10.8^{\mathrm{a}}$ \\
$>5$ min & $38.5^{\mathrm{b}}$ & $41.0^{\mathrm{b}}$ \\
Birth intervention & & \\
$\quad$ No & $9.0^{\mathrm{a}}$ & $13.4^{\mathrm{a}}$ \\
Yes & $5.1^{\mathrm{a}}$ & $6.3^{\mathrm{a}}$ \\
Sex & & \\
$\quad$ Male & $8.0^{\mathrm{a}}$ & $13.6^{\mathrm{a}}$ \\
Female & $9.1^{\mathrm{a}}$ & $11.6^{\mathrm{a}}$ \\
Umbilical cord integrity & & \\
Intact & $8.9^{\mathrm{a}}$ & $13.0^{\mathrm{a}}$ \\
Broken & $7.8^{\mathrm{a}}$ & $11.9^{\mathrm{a}}$ \\
\hline
\end{tabular}

a,b Values with different superscripts within the same column within variable differ significantly $(p<0.05)$.

had a lower ADG at day 7 ( $\mathrm{p}<0.001$, Table 5). Piglets without birth intervention had lower growth than piglets with birth intervention (161.1 \pm 2.8 vs $182.4 \pm 7.7 \mathrm{~g} / \mathrm{d}, \mathrm{p}=0.010$, Table 6). Male piglets had higher growth than female piglets $(169.1 \pm 3.7$ vs $157.6 \pm 3.9$ $\mathrm{g} / \mathrm{d}, \mathrm{p}=0.032$, Table 6). Piglets that attempted to stand after $5 \mathrm{~min}$ $(127.1 \pm 13.6 \mathrm{~g} / \mathrm{d})$ had lower growth than piglets that attempted to stand within $1 \mathrm{~min}(165.9 \pm 2.9 \mathrm{~g} / \mathrm{d}, \mathrm{p}=0.006)$ or within 1 to $5 \mathrm{~min}(156.3 \pm 13.6 \mathrm{~g} / \mathrm{d}, \mathrm{p}=0.071$, Table 6).

Factors associated with average daily gain until day 21 after birth: Piglet $\mathrm{BW}_{\mathrm{B}}(\mathrm{p}<0.001)$ and blood glucose concentration ( $\mathrm{p}$ $=0.009)$ positively influenced piglet $\mathrm{ADG}$ at day $21(\mathrm{r}=0.106$, $\mathrm{p}<0.01$, Table 5). Piglets born from sows with higher TB and BA had lower ADG at day 21 (Table 5, p<0.001). Piglets without birth intervention had lower growth than piglets with birth intervention (214.3 \pm 2.7 vs $235.1 \pm 7.3 \mathrm{~g} / \mathrm{d}, \mathrm{p}=0.008$, Table 6). Piglets that attempted to stand after $5 \mathrm{~min}(190.3 \pm 13.1 \mathrm{~g} / \mathrm{d})$ had lower growth

Table 2. Potential indicators for piglet pre-weaning mortality (means \pm standard error of the mean) comparing surviving piglets from birth to day 7 of lactation ( $n=631$ ) with dying piglets $(n=59)$

\begin{tabular}{lcrc}
\hline Variables & Surviving & Dying & p-value \\
\hline Total number of piglets born per litter & $14.9 \pm 0.14$ & $15.6 \pm 0.43$ & 0.171 \\
Number of piglets born alive per litter & $13.0 \pm 0.12$ & $13.3 \pm 0.45$ & 0.491 \\
Litter size after cross-fostering & $13.2 \pm 0.07$ & $13.7 \pm 0.22$ & 0.038 \\
Birth interval $(\mathrm{min})$ & $14.9 \pm 0.80$ & $9.5 \pm 1.72$ & 0.005 \\
Birth weight $(\mathrm{kg})$ & $1.52 \pm 0.01$ & $1.11 \pm 0.05$ & $<0.001$ \\
Birth order & $7.5 \pm 0.18$ & $8.5 \pm 0.59$ & 0.130 \\
Heart rate (bpm) & $66.5 \pm 1.34$ & $62.5 \pm 3.68$ & 0.381 \\
Glucose (mg/dL) & $49.3 \pm 0.70$ & $47.8 \pm 2.69$ & 0.605 \\
Oxygen saturation $(\%)$ & $91.3 \pm 0.36$ & $90.4 \pm 0.99$ & 0.458 \\
Rectal temperature at $24 \mathrm{~h}\left({ }^{\circ} \mathrm{C}\right)$ & $38.7 \pm 0.02$ & $38.2 \pm 0.14$ & $<0.001$ \\
\hline
\end{tabular}


Table 4. Potential indicators for piglet pre-weaning mortality (means \pm standard error of the mean) comparing surviving piglets from birth to day 21 of lactation ( $\mathrm{n}=603$ ) with dying piglets $(n=87)$

\begin{tabular}{|c|c|c|c|}
\hline Variables & Surviving & Dying & $p$-value \\
\hline Total number of piglets born per litter & $14.9 \pm 0.14$ & $15.9 \pm 0.33$ & 0.010 \\
\hline Number of piglets born alive per litter & $12.9 \pm 0.12$ & $13.7 \pm 0.32$ & 0.028 \\
\hline Litter size after cross-fostering & $13.2 \pm 0.07$ & $13.6 \pm 0.18$ & 0.042 \\
\hline Birth interval (min) & $15.2 \pm 0.83$ & $9.3 \pm 1.37$ & $<0.001$ \\
\hline Birth weight (kg) & $1.53 \pm 0.01$ & $1.16 \pm 0.05$ & $<0.001$ \\
\hline Birth order & $7.5 \pm 0.19$ & $8.1 \pm 0.45$ & 0.319 \\
\hline Heart rate (bpm) & $66.9 \pm 1.39$ & $61.4 \pm 2.71$ & 0.076 \\
\hline Glucose (mg/dL) & $49.5 \pm 0.71$ & $46.6 \pm 2.13$ & 0.156 \\
\hline Oxygen saturation (\%) & $91.2 \pm 0.37$ & $91.3 \pm 0.80$ & 0.872 \\
\hline Rectal temperature at $24 \mathrm{~h}\left({ }^{\circ} \mathrm{C}\right)$ & $38.7 \pm 0.02$ & $38.3 \pm 0.10$ & $<0.001$ \\
\hline
\end{tabular}

Table 5. Pearson's correlations among the most significant potential predictor measured during farrowing and soon after birth and average daily gain (ADG) of the piglets from birth until 7 and 21 days of age

\begin{tabular}{|c|c|c|c|c|c|c|}
\hline & TB & BA & $\mathrm{BI}$ & $\mathrm{BW}_{\mathrm{B}}$ & HR & GLU \\
\hline $\mathrm{BA}$ & $0.798^{* * *}$ & - & - & - & - & - \\
\hline $\mathrm{Bl}$ & $-0.138^{* * *}$ & $-0.128^{* * *}$ & - & - & - & - \\
\hline $\mathrm{BW}_{\mathrm{B}}$ & $-0.309^{* * *}$ & $-0.348^{* * *}$ & $0.180^{* * *}$ & - & - & - \\
\hline$H R$ & $-0.092^{*}$ & $-0.077^{*}$ & - & - & - & - \\
\hline $\mathrm{SatO}_{2}$ & - & - & - & - & $-0.179 * * *$ & - \\
\hline GLU & $-0.118^{* *}$ & $-0.136^{* * *}$ & $0.146^{* * *}$ & $0.187^{* * *}$ & - & - \\
\hline RT24h & - & - & - & $0.128^{* * *}$ & - & - \\
\hline ADG7 & $-0.272^{* * *}$ & $-0.283^{* * *}$ & - & $0.430^{* * *}$ & - & $0.172^{* * *}$ \\
\hline ADG21 & $-0.197^{* * *}$ & $-0.284^{* * *}$ & - & $0.431^{* * *}$ & - & $0.106^{* *}$ \\
\hline
\end{tabular}

$\mathrm{TB}$, total number of piglets born per litter; $\mathrm{BA}$, number of piglets born alive per litter; $\mathrm{BI}$, birth interval; $\mathrm{BW}_{\mathrm{B}}$, birth weight; $\mathrm{HR}$, heart rate; GLU, blood glucose concentration; Sat ${ }_{2}$, blood oxygen saturation; RT24h, rectal temperature at $24 \mathrm{~h}$ after birth; ADG7, average daily gain from birth until day 7; ADG21, average daily gain from birth until day 21.

Significance levels: ${ }^{*} p<0.05,{ }^{* *} p<0.01,{ }^{* * *} p<0.001$.

than piglets that attempted to stand within $1 \mathrm{~min}(218.0 \pm 2.8 \mathrm{~g} / \mathrm{d}$, $\mathrm{p}=0.039$, Table 6).

Table 6. Categorical variables influencing average daily gain (means \pm standard error of the mean) at day 7 and 21 after birth from univariate analyses

\begin{tabular}{lcc}
\hline Variables & \multicolumn{2}{c}{ Average daily gain (g/d) } \\
\cline { 2 - 3 } & Day 7 & Day 21 \\
\hline Skin color & & \\
$\quad$ Normal & $163.6 \pm 2.7^{\mathrm{a}}$ & $217.0 \pm 2.6^{\mathrm{a}}$ \\
$\quad$ Pale & $164.4 \pm 14.4^{\mathrm{a}}$ & $210.6 \pm 14.5^{\mathrm{a}}$ \\
Time attempted to stand & & \\
$\quad<1$ min & $165.9 \pm 2.8^{\mathrm{a}}$ & $218.0 \pm 2.8^{\mathrm{a}}$ \\
$\quad 1$ to 5 min & $156.3 \pm 8.7^{\mathrm{ab}}$ & $215.9 \pm 8.3^{\mathrm{ab}}$ \\
$>5$ min & $127.1 \pm 13.7^{\mathrm{b}}$ & $190.3 \pm 13.1^{\mathrm{b}}$ \\
Birth intervention & & \\
$\quad$ No & $161.1 \pm 2.8^{\mathrm{a}}$ & $214.3 \pm 2.7^{\mathrm{a}}$ \\
$\quad$ Yes & $182.4 \pm 7.7^{\mathrm{b}}$ & $235.1 \pm 7.3^{\mathrm{b}}$ \\
Sex & & \\
$\quad$ Male & $169.1 \pm 3.7^{\mathrm{a}}$ & $219.1 \pm 3.6^{\mathrm{a}}$ \\
$\quad$ Female & $157.6 \pm 3.9^{\mathrm{b}}$ & $214.4 \pm 3.7^{\mathrm{a}}$ \\
Umbilical cord integrity & & \\
$\quad$ Intact & $160.4 \pm 3.2^{\mathrm{a}}$ & $215.6 \pm 3.1^{\mathrm{a}}$ \\
Broken & $170.6 \pm 4.7^{\mathrm{a}}$ & $219.4 \pm 4.5^{\mathrm{a}}$ \\
\hline
\end{tabular}

a,b Values with different superscripts within the same column within variable differ significantly $(p<0.05)$.

\section{Multivariate analyses}

Average daily gain: The final multi-covariate model for ADG at day 7 included $\mathrm{BW}_{\mathrm{B}}(\mathrm{p}<0.001)$, blood glucose concentration $(\mathrm{p}<$ $0.001), B A(p=0.025), \operatorname{sex}(p=0.087)$, and attempts to stand ( $p$ $=0.093)$ (Table 7). At day 7 , the piglets with $\mathrm{BW}_{\mathrm{B}}<1.30 \mathrm{~kg}$ had a lower ADG than the piglets with $\mathrm{BW}_{\mathrm{B}} \geq 1.80 \mathrm{~kg}(\mathrm{p}<0.001)$ and the piglets with $\mathrm{BW}_{\mathrm{B}} 1.30$ to $1.79 \mathrm{~kg}(\mathrm{p}<0.001$, Table 7). The piglets with a blood glucose concentration of $\leq 24 \mathrm{mg} / \mathrm{dL}$ had a lower ADG at day 7 than the piglets with a blood glucose concentration of $>24 \mathrm{mg} / \mathrm{dL}$ ( $\mathrm{p}<0.001$, Table 7 ). Furthermore, the piglets with a low BA ( $<12$ piglet) had a higher ADG at day 7 than the piglets with 12 to $14 \mathrm{BA}(\mathrm{p}=0.087)$ and the piglets with $\geq 15 \mathrm{BA}$ $(\mathrm{p}=0.030$, Table 7$)$. The male piglets tended to have a higher ADG at day 7 than the female piglets $(p=0.087$, Table 7$)$. The piglets that stood within $1 \mathrm{~min}$ tended to have a higher ADG at day 7 than the piglets that stood after $5 \mathrm{~min}(\mathrm{p}=0.075$, Table 7).

Based on a multivariate statistical model, factors significantly influencing ADG of the piglets at day 21 in the final model included $\mathrm{BW}_{\mathrm{B}}(\mathrm{p}<0.001), \mathrm{BA}(\mathrm{p}<0.001)$, and blood glucose concentration $(\mathrm{p}=0.042)$. The statistical model revealed that, at day 21 , the piglets with $\mathrm{a} \mathrm{BW}_{\mathrm{B}}$ of $<1.30 \mathrm{~kg}$ had a lower $\mathrm{ADG}$ than the piglets with a $\mathrm{BW}_{\mathrm{B}}$ of $\geq 1.80 \mathrm{~kg}(\mathrm{p}<0.001)$ and the piglets with $\mathrm{a} \mathrm{BW}_{\mathrm{B}} 1.30$ to $1.79 \mathrm{~kg}(\mathrm{p}<0.001)$ (Table 7). The piglets from litters with a low 
Table 7. Predictive factors included in the final models for average daily gain (least square means \pm standard error of the mean) from birth until 7 and 21 days of life from multivariate analyses

\begin{tabular}{|c|c|c|}
\hline \multirow{2}{*}{ Variables } & \multicolumn{2}{|c|}{ Average daily gain (g/d) } \\
\hline & Day 7 & Day 21 \\
\hline \multicolumn{3}{|c|}{ Number of piglets born alive per litter, piglets } \\
\hline$<12$ & $150.6 \pm 11.09^{\mathrm{aA}}$ & $226.8 \pm 9.88^{\mathrm{a}}$ \\
\hline 12 to 14 & $126.4 \pm 11.39^{\mathrm{abB}}$ & $190.6 \pm 9.60^{b}$ \\
\hline$\geq 15$ & $121.3 \pm 11.16^{b}$ & $192.8 \pm 9.94^{b}$ \\
\hline \multicolumn{3}{|l|}{ Birth weight (kg) } \\
\hline$<1.30$ & $88.9 \pm 9.72^{c}$ & $165.5 \pm 9.01^{c}$ \\
\hline 1.30 to 1.79 & $145.3 \pm 9.52^{b}$ & $210.5 \pm 8.45^{b}$ \\
\hline$\geq 1.80$ & $164.2 \pm 10.59^{\mathrm{a}}$ & $234.2 \pm 9.40^{\mathrm{a}}$ \\
\hline \multicolumn{3}{|l|}{ Glucose (mg/dL) } \\
\hline$\leq 24$ & $107.8 \pm 15.32^{b}$ & $190.3 \pm 15.95^{b}$ \\
\hline$>24$ & $157.8 \pm 6.16^{\mathrm{a}}$ & $220.6 \pm 4.99^{\mathrm{a}}$ \\
\hline \multicolumn{3}{|l|}{ Sex } \\
\hline Male & $136.5 \pm 9.45^{A}$ & NS \\
\hline Female & $129.1 \pm 9.53^{B}$ & NS \\
\hline \multicolumn{3}{|c|}{ Attempt to stand (min) } \\
\hline$<1$ & $141.8 \pm 8.27^{A}$ & NS \\
\hline 1 to 5 & $140.2 \pm 10.78^{A B}$ & NS \\
\hline$>5$ & $116.4 \pm 13.87^{B}$ & NS \\
\hline
\end{tabular}

a,b,c Values with different small superscripts within the same column differ significantly $(\mathrm{p}<0.001)$

${ }_{A, B}$ Values with different capital superscripts within the same column tended to be differences $(0.05<p<0.10)$.

$N S$, the variables were not significant $(p>0.01)$ and were not included in the final models.

BA ( $<12$ piglets) had a higher ADG at day 21 than those from litters with a BA of 12 to $14(\mathrm{p}<0.001)$ and $\geq 15(\mathrm{p}<0.001)$. The piglets with a blood glucose concentration of $\leq 24 \mathrm{mg} / \mathrm{dL}$ had a lower ADG at day 21 than the piglets with a blood glucose concentration of $>24 \mathrm{mg} / \mathrm{dL}(\mathrm{p}=0.042)$. Sex and attempts to stand did not influence ADG of the piglet at day 21 ( $\mathrm{p}>0.10)$.

Piglet pre-weaning mortality: The final multivariate model for mortality at day 7 included $\mathrm{BW}_{\mathrm{B}}$ and $\mathrm{RT} 24 \mathrm{~h}(\mathrm{p}<0.001)$. At day 7 , the piglets with $\mathrm{BW}_{\mathrm{B}}<1.30 \mathrm{~kg}$ had a higher $(\mathrm{p}<0.001)$ mortality rate (19.0\%) than the piglets with $B_{B} \geq 1.80 \mathrm{~kg}(3.3 \%)$ and piglets with $\mathrm{BW}_{\mathrm{B}} 1.30$ to $1.79 \mathrm{~kg}$ (4.0\%, Figure 1). The piglets with $\mathrm{RT} 24 \mathrm{~h}<37.0^{\circ} \mathrm{C}$ had a higher $(\mathrm{p}<0.001)$ mortality rate $(86.2 \%)$ at day 7 than the piglets with $\mathrm{RT} 24 \mathrm{~h} 37.0^{\circ} \mathrm{C}$ to $38.5^{\circ} \mathrm{C}(7.3 \%)$ and $\mathrm{RT} 24 \mathrm{~h}>38.5^{\circ} \mathrm{C}$ (3.9\%, Figure 2$)$.

Based on a multivariate statistical model, factors influencing piglet mortality at day 21 included $\mathrm{BW}_{\mathrm{B}}(\mathrm{p}<0.001)$ and RT24h $(\mathrm{p}<0.001)$. At day 21 , the piglets with $\mathrm{BW}_{\mathrm{B}}<1.30 \mathrm{~kg}$ had a higher $(\mathrm{p}<0.001)$ mortality rate $(26.4 \%)$ than the piglets with $\mathrm{BW}_{\mathrm{B}} \geq 1.80$ $\mathrm{kg}(6.0 \%)$ and the piglets with $\mathrm{BW}_{\mathrm{B}} 1.30$ to $1.79 \mathrm{~kg}(6.5 \%$, Figure 1). The piglets with $\mathrm{RT} 24 \mathrm{~h}<37.0^{\circ} \mathrm{C}$ had a higher $(\mathrm{p}<0.001)$ mortality rate (89.7\%) at day 21 than the piglets with RT24h $37.0^{\circ} \mathrm{C}$ to $38.5^{\circ} \mathrm{C}(12.9 \%)$ and $\mathrm{RT} 24 \mathrm{~h}>38.5^{\circ} \mathrm{C}(7.0 \%$, Figure 2$)$.

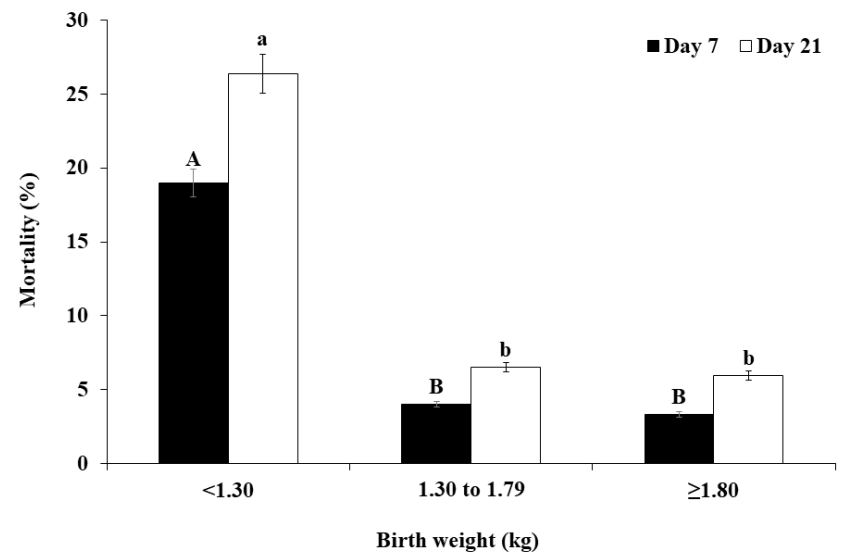

Figure 1. Percentage of mortality at days 7 and 21 for all piglets classified into low $(<1.30 \mathrm{~kg}, \mathrm{n}=216)$, medium (1.30 to $1.79 \mathrm{~kg}, \mathrm{n}=323)$ and high ( $\geq 1.80 \mathrm{~kg}, \mathrm{n}=$ 151) birth weight categories. ${ }^{A, B, a, b}$ Values with different superscripts within the same day differ significantly $(p<0.05)$.

The main objective of this study was to determine the effect of certain newborn piglet traits measured soon after birth on piglet pre-weaning mortality and growth. As expected, $\mathrm{BW}_{\mathrm{B}}$ and $\mathrm{RT} 24 \mathrm{~h}$ were the most influential postnatal survival factors at both day 7 and at weaning. Furthermore, $\mathrm{BW}_{\mathrm{B}}, \mathrm{BA}$ and blood glucose concentration significantly influenced piglet growth during the whole lactation period, while sex and time spent attempting to stand had some impact on their growth up to day 7 .

In agreement with our results, many studies have identified piglet $\mathrm{BW}_{\mathrm{B}}$ as the main predictor for both survival and growth during lactation $[9,15]$. Piglet $\mathrm{BW}_{\mathrm{B}}$ is positively associated with their physiological maturity and, in turn, correlates with different physical and physiological parameters such as colostrum intake capacity and thermoregulation ability [3]. Small piglets usually have decreased viability and a lower capacity to compete for a teat [16]. Johansen et al [17] found that piglets with a low $\mathrm{BW}_{\mathrm{B}}$ often have lower $\mathrm{ADG}$ in the suckling period. In addition,

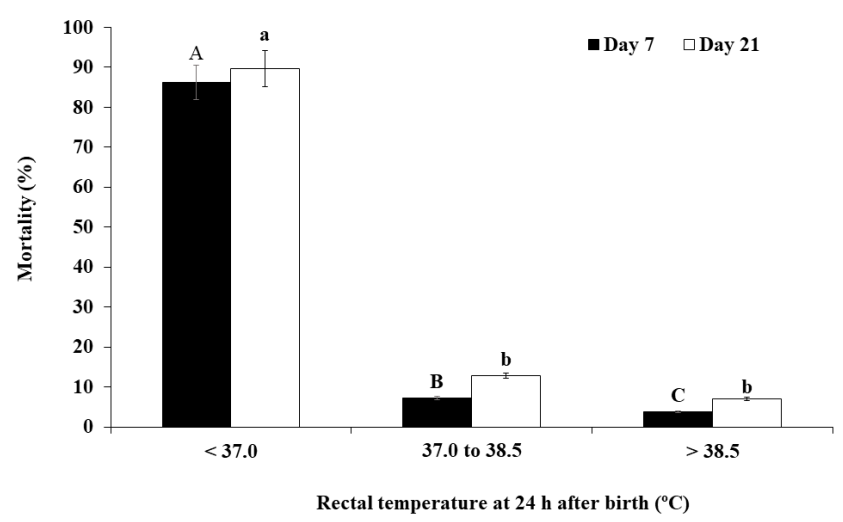

Figure 2. Percentage of mortality at days 7 and 21 for all piglets classified into low $\left(<37.0^{\circ} \mathrm{C}, \mathrm{n}=29\right)$, medium $\left(37.0^{\circ} \mathrm{C}\right.$ to $\left.38.5^{\circ} \mathrm{C}, \mathrm{n}=248\right)$ and high $\left(>38.5^{\circ} \mathrm{C}, \mathrm{n}=\right.$ 413) rectal temperature categories at $24 \mathrm{~h}$ after birth. ${ }^{A, B, C, a, b, c}$ Values with different superscripts within the same day differ significantly $(p<0.05)$. 
low $\mathrm{BW}_{\mathrm{B}}$ piglets are less able to maintain body temperature [18] which leads to starvation, lethargy and increased risk of crushing by the sow. Therefore, lower $\mathrm{BW}_{\mathrm{B}}$ piglets may also show a low nutritional status and poor passive immunity [19]. In agreement with our results, rectal temperature after birth was identified as an important indicator for piglet survival $[9,16]$, indicating that piglets with low rectal temperature after $24 \mathrm{~h}$ might have lower thermoregulation abilities. Thermoregulation is a crucial physiological event for all newborn piglets. The piglets that die during the first days of life are not able to maintain optimal rectal temperature during the first $24 \mathrm{~h}$ of life [10]. In the present study, RT24h was significantly associated with mortality rate but was not related with ADG. In contrast, Panzardi et al [9] identified RT24h as an indicator for piglet growth at weaning. Likewise, Pedersen et al [20] found that piglets with low RT24h had low ADG from birth to weaning. One possible explanation might be due to that the piglets with low RT24h may consume less colostrum than the piglets with high RT24h. Thus, growth rate of these piglets might be compromise.

In the current study, BA was observed to influence piglet growth. Likewise, other studies found that BA negatively correlated with the piglet weaning weight [20]. This might be due to the fact that there is also an increase in the number of small piglets in the litter with an increased BA [21]. The present study also demonstrated that $\mathrm{BW}_{\mathrm{B}}$ of the piglets was significantly decreased when TB increased (Table 5). Competition between littermates might have a negative impact on piglet colostrum intake, especially in the small piglets, resulting in reduced growth during lactation [3]. Moreover, BA was not related with mortality in the present study, whereas in the previous study, there was a positive relationship between the number of piglets in the litter and piglet mortality [2]. Nonetheless, Muns et al [8] and Pedersen et al [20] found a relationship between BA and piglet growth, but not between $\mathrm{BA}$ and mortality rate.

In the present study, blood glucose concentration at birth was a significant predictor for piglet ADG at 7 and 21 days of life but not for piglet mortality. Accordingly, studies failed to demonstrate a correlation between blood glucose concentration in newborn piglet and their survival $[10,15,16]$. However, Panzadi et al [9] found that either too low ( 24 to $30 \mathrm{mg} / \mathrm{dL}$ ) or too high (45 to 162 $\mathrm{mg} / \mathrm{dL}$ ) levels of blood glucose in neonatal piglets were associated with an increased pre-weaning mortality. In the present study, piglets with high glucose concentrations at birth might have high energy reserves and, subsequently, enhanced capacity for suckling and growth. This implies that some source of glucose or energy supplementation in neonatal piglets maybe needed to improve the suckling capacity and growth performance in the neonatal piglets.

In the multivariate models for $\mathrm{ADG}$ at day 7, time from birth to first attempts to stand was also identified as a predictive factor. In the present study, piglets spending $>5 \mathrm{~min}$ from birth to first attempts to stand had low ADG. Decaluwé et al [12] also found that piglets spending a long time from birth to suckling had a lower ADG during the lactation period than those spending a short time from birth to suckling. Moreover, neonatal piglets spending a short time from birth to first attempts to stand resulted in a low pre-weaning mortality $[9,10]$. However, Leenhouwers et al [22] found no relationship between time from birth to first attempts to stand and piglet mortality rate during the first week of lactation. Nonetheless, time elapsed from birth to first suckling significantly influences colostrum intake of the piglets [23]. Therefore, "the time elapsed from birth to first suckling" has been included in a formula for estimating colostrum consumption in piglets [23]. In the present study, piglets spending a short time period from birth to first attempts to stand are probably faster at first suckling, thus increasing their colostrum consumption. The colostrum consumption of the neonatal piglets significantly influence the piglet survival and passive immunity [24]. Therefore, in practice, newborn piglets spending more than $5 \mathrm{~min}$ to first attempt to stand need special cares.

In conclusion, low $\mathrm{BW}_{\mathrm{B}}$ and low $\mathrm{RT} 24 \mathrm{~h}$ compromise piglet survival during the lactation period in the tropical conditions. In addition, piglets in the litters with a high number of BA and piglets with low $\mathrm{BW}_{\mathrm{B}}$ and/or low blood glucose concentration have reduced body weight growth during lactation.

\section{CONFLICT OF INTEREST}

We certify that there is no conflict of interest with any financial organization regarding the material discussed in the manuscript.

\section{ACKNOWLEDGMENTS}

Financial support for the present study was provided by a grant for International Research Integration: Chula Research Scholar, Ratchadaphiseksomphot Endowment Fund. M. Nuntapaitoon is a grantee of the Research and Researchers for Industries (RRI) Ph.D. program and the Thailand Research Fund, and part of the research grant was supported by the Rachadapisek Sompote Endowment Fund for the 90th Anniversary of Chulalongkorn University. Ramon Muns was supported by the Rachadapisek Sompote Endowment Fund for Postdoctoral Fellowship by Chulalongkorn University.

\section{REFERENCES}

1. Knox R. Getting to 30 pigs weaned/sow/year. Proceedings of London Swine Conference, 2005; London, UK. pp. 47-59.

2. Nuntapaitoon M, Tummaruk P. Piglets pre-weaning mortality in a commercial swine herd in Thailand. Trop Anim Health Prod 2015; 47:1539-46

3. Muns R, Nuntapaitoon M, Tummaruk P. Non-infectious causes of pre-weaning mortality in piglets. Livest Sci 2016;184:46-57.

4. Shankar BP, Madhusudhan HS, Harish DB. Pre-weaning mortality 
in pig-causes and management. Vet World 2009;2:236-9.

5. Campos PHRF, Silva BAN, Donzele JL, Oliveira RFM, Knol EF. Effects of sow nutrition during gestation on within-litter birth weight variation: a review. Animal 2012;6:797-806.

6. Vallet JL, Miles JR. Comparison of myelination between large and small pig fetuses during late gestation. Anim Reprod Sci 2012;132: 50-7.

7. Herpin P, Le Dividich J, Hulin JC, et al. Effect of the level of asphyxia during delivery on viability at birth and early postnatal vitality of newborn pigs. J Anim Sci 1996;74:2067-75.

8. Muns R, Manzanilla EG, Sol C, Manteca X, Gasa J. Piglet behaviour as a measure of vitality and its influence on piglet survival and growth during lactation. J Anim Sci 2013;91:1838-43.

9. Panzardi A, Bernardi ML, Mellagi AP, et al. Newborn piglet traits associated with survival and growth performance until weaning. Prev Vet Med 2013;110:206-13.

10. Baxter EM, Jarvis S, D'Eath RB, et al. Investigating the behavioural and physiological indicators of neonatal survival in pigs. Theriogenology 2008;69:773-83.

11. Pedersen LJ, Malmkvist J, Kammersgaard T, Jørgensen E. Avoiding hypothermia in neonatal pigs: effect of duration of floor heating at different room temperatures. J Anim Sci 2013;91:425-32.

12. Decaluwé R, Maes D, Wuyts B, et al. Piglets'colostrum intake associates with daily weight gain and survival until weaning. Livest Sci 2014;162: $185-92$.

13. Committee on Nutrient Requirements of Swine, National Research Council. Nutrient requirements of swine. 11th ed. Washington, DC, USA: National Academy Press; 2012.

14. SAS Institute Inc. SAS User's guide. Statistics version 9.0 Cary, NC,
USA: SAS Institute Inc.; 1996.

15. Rootwelt V, Reksen O, Farstad W, Framstad T. Postpartum deaths: piglet, placental, and umbilical characteristics. J Anim Sci 2013;91: 2647-56.

16. Tuchscherer M, Puppe B, Tuchscherer A, Tiemann U. Early identification of neonates at risk: traits of newborn piglets with respect to survival. Theriogenology 2000;54:371-88.

17. Johansen M, Alban L, Kjærsgård HD, Bæbo P. Factors associated with sucking piglet average daily gain. Prev Vet Med 2004;63:91-102.

18. Theil PK, Nielsen MO, Sørensen MT, Lauridsen C. Lactation, milk and suckling. In: Bach KKE, Kjeldsen NJ, Poulsen HD, Jensen BB, editors. Nutritional physiology of pigs. Copenhagen, Denmark: Pig Research Centre; 2012. pp. 49.

19. Quiniou N, Dagorn J, Gaudré D. Variation of piglets' birth weight and consequences on subsequent performance. Livest Prod Sci 2002; 78:63-70.

20. Pedersen LJ, Schild SLA, Malmkvist J. The influence of the thermal environment and other early life events on growth rate of piglets during lactation. Animal 2015;9:1529-35.

21. Quesnel H, Brossard L, Valancogne A, Quiniou N. Influence of some sow characteristics on within-litter variation of piglet birth weight. Animal 2008;2:1842-9.

22. Leenhouwers JI, de Almeida Jr CA, Knol EF, van der Lende T. Progress of farrowing and early postnatal pig behavior in relation to genetic merit for pig survival. J Anim Sci 2001;79:1416-22.

23. Devillers N, van Milgen J, Prunier A, Le Dividich J. Estimation of colostrum intake in the neonatal pig. Anim Sci 2004;78:305-13.

24. Devillers N, Le Dividich J, Prunier A. Influence of colostrum intake on piglet survival and immunity. Animal 2011;5:1605-12. 